\title{
PFKM gene defect and glycogen storage disease GSDVII with misleading enzyme histochemistry
}

\section{OPEN}

Mari Auranen, $\mathrm{MD}, \mathrm{PhD}$ Johanna Palmio, MD,

$\mathrm{PhD}$

Emil Ylikallio, MD, PhD

Sanna Huovinen, MD

Anders Paetau, MD, PhD

Satu Sandell, MD, PhD

Hannu Haapasalo, MD,

$\mathrm{PhD}$

Kati Viitaniemi, MSc

Päivi Piirilä, MD, PhD

Henna Tyynismaa, PhD

Bjarne Udd, MD, PhD

Correspondence to

Dr. Auranen:

mari.auranen@hus.fi

\section{ABSTRACT}

Objective: To elaborate the diagnostic methods used as "gold standard" in one of the most common glycogen storage diseases (GSDs), Tarui disease (GSDVII).

Methods: Two siblings with disease suggestive of GSD underwent thorough clinical analysis, including muscle biopsy, muscle MRI, exercise tests, laboratory examinations, and wholeexome sequencing (WES).

Results: Both siblings had juvenile-onset exercise intolerance with cramping and infrequent myoglobinuria. Muscle biopsy showed extralysosomal glycogen accumulation, but because of normal phosphofructokinase histochemistry, GSDVII was thought to be excluded. However, WES revealed a causative homozygous PFKM gene defect, R39Q, in both siblings, establishing the diagnosis of GSDVII, which was confirmed by very low residual phosphofructo-1-kinase (PFK) enzyme activity in biochemical studies.

Conclusions: We suggest that in patients with suspicion of GSD and extralysosomal glycogen accumulation, biochemical activity assay of PFK followed by molecular genetics should be performed even when enzyme histochemistry is normal. Neurol Genet 2015;1:e7; doi: 10.1212/ NXG.0000000000000007

\section{GLOSSARY}

$\mathbf{C K}=$ creatine kinase; $\mathbf{E M}=$ electron microscopy; GSD = glycogen storage disease; $\mathbf{L C 3} \mathbf{b}=$ light chain $\mathbf{3 b} ; \mathbf{P A S}=$ periodic acid-Schiff; PFK = phosphofructo-1-kinase; PFKM = muscle phosphofructokinase; VCP = valosin-containing protein; WES $=$ whole-exome sequencing

Muscle phosphofructokinase (PFKM) deficiency (glycogen storage disease [GSD] VII, Online Mendelian Inheritance in Man \#232800, or Tarui disease) is an autosomal recessive disorder characterized by exercise-induced muscle weakness, pain, cramping, myoglobinuria, and hemolysis. ${ }^{1-4}$ Besides the classic phenotype, 3 additional forms of the disease have been reported: a severe infantile form with hypotonia, progressive myopathy, cardiomyopathy, respiratory failure, and early death; a late-onset form with fixed proximal weakness; and a form with hemolytic anemia without muscle symptoms. ${ }^{4}$

The defective enzyme, phosphofructo-1-kinase (PFK, E.C. 2.7.1.11), is a tetrameric enzyme composed of 3 subunits - muscle $(\mathrm{M})$, liver $(\mathrm{L})$, and platelet $(\mathrm{P})$ — encoded by different genes. PFK is responsible for catalyzing the phosphorylation of fructose 6-phosphate to fructose 1,6-bisphosphate, which is considered to be one of the rate-limiting steps of glycolysis. In skeletal muscle, only the homotetramer $\mathrm{M}$ is expressed, making muscle solely dependent on the function of PFKM in utilization of glucose. In blood erythrocytes, however, 5 different tetramers of PFKM and PFKL are present. Accordingly, patients with GSDVII usually show

\footnotetext{
From the Research Programs Unit (M.A., E.Y., H.T.), Molecular Neurology, Biomedicum Helsinki, University of Helsinki, Helsinki, Finland; Clinical Neurosciences (M.A.), Neurology, University of Helsinki and Helsinki University Hospital, Helsinki, Finland; Neuromuscular Research Center (J.P., S.S., K.V., B.U.), Tampere University Hospital and University of Tampere, Tampere, Finland; Department of Pathology (S.H., H.H.), Fimlab Laboratories, University Hospital and University of Tampere, Tampere, Finland; Department of Pathology (A.P.), HUSLAB, University of Helsinki and Helsinki University Hospital, Helsinki, Finland; Department of Neurology (S.S.), Seinäjoki Central Hospital, Seinäjoki, Finland; and Unit of Clinical Physiology (P.P.), HUS Medical Imaging Center, Helsinki University Hospital, Helsinki, Finland.

Funding information and disclosures are provided at the end of the article. Go to Neurology.org/ng for full disclosure forms. The Article Processing Charge was paid by the authors.

This is an open access article distributed under the terms of the Creative Commons Attribution-NonCommercial-NoDerivatives License 4.0 (CC BY-NC-ND), which permits downloading and sharing the work provided it is properly cited. The work cannot be changed in any way or used commercially.
} 
severe reduction of enzyme activity in their skeletal muscle tissue and partial deficiency in blood erythrocytes. ${ }^{2}$

We describe 2 siblings with the classic phenotype of GSDVII but with normal muscle biopsy enzyme histochemistry for myophosphorylase and phosphofructokinase repeated in 2 different laboratories. However, a homozygous PFKM gene mutation, R39Q, was identified in both siblings by whole-exome sequencing (WES), suggesting that GSDVII cannot be excluded by normal enzyme histochemistry.

METHODS Patients. The male patient, P1, was the oldest of 5 siblings. His younger sister, P2, had been investigated previously due to similar symptoms, but other family members were healthy. No family history of consanguinity was evident. Both patients had normal motor development and milestones and normal exercise tolerability in childhood. Exercise-related symptoms started in the early teens. Thorough investigations in adulthood included clinical examination, electroneuromyography, muscle MRI, exercise tests, muscle biopsy, and laboratory investigations.

Standard protocol approvals, registrations, and patient consents. Blood samples were taken from patients in accordance with the Declaration of Helsinki after informed consent was obtained.

Muscle biopsy and enzymatic studies. Muscle biopsies were taken from tibialis anterior (P1: age 58 years; P2: age 51 years) and vastus lateralis (P2: age 47 years). Standard methods were used in cryosection and electron microscopy (EM) analyses. Immunohistochemistry with the following antibodies was performed: PFKM (PAB2142; Abnova, Taipei, Taiwan), ubiquitin (Z458; Dako, Algol Diagnostics Oy, Espoo, Finland), p62 (Sigma-Aldrich, St. Louis, $\mathrm{MO}$ ), valosin-containing protein (VCP, MA3-004; Thermo Scientific, Waltham, MA), desmin (MU 072-UC; Biogenx, Fremont, CA), LC3b (light chain 3b, 2775; Cell Signaling Technology, Danvers, MA), and myotilin (NCL-MYOTILIN; Novocastra, Leica Microsystems Inc., Buffalo Grove, IL). Biochemical activity of phosphofructokinase was measured at the Institute of Biology and Pathology in Centre Hospital de Grenoble.

Molecular genetic studies. Total DNA was extracted from peripheral blood leukocytes by standard methods. The NimbleGen Sequence Capture 2.1 M Human Exome v2.0 array was used, and sequencing was performed on an Illumina Genome Analyzer-IIx platform using $2 \times 82$ bp paired-end reads. Sequence alignment to the hg19 assembly was done according to the variant calling pipeline developed by the Finnish Institute for Molecular Medicine. ${ }^{5}$ The procedure yielded $60 \times$ and $44 \times$ mean target coverage in $\mathrm{P} 1$ and $\mathrm{P} 2$, respectively. Sanger sequencing of exon 2 of the PFKM gene was done using the oligonucleotide primers 5'-CGCCTTTTCTTAGGAGCAAC-3' and 5'-GGTCCCACCATCACTATTGG-3' .

RESULTS Patients. P1 was healthy until age 12, when strong attacks of muscle pain, weakness, cramping, and vomiting occurred rapidly during strenuous exercise. Muscle pain lasted several days after exercise. He was never hospitalized due to these attacks, but he began to avoid intensive exercise. He could walk
$10 \mathrm{~km}$ at his own pace but could not run. Examinations at age 58 revealed mild muscle weakness in hip flexors and extensors and ankle flexors and extensors on the right side, mild reticulocytosis without anemia, and normal EMG. Measured creatine kinase (CK) values were normal or somewhat elevated to a maximum of $580 \mathrm{U} / \mathrm{L}$ at rest (normal CK values 40-280 U/L). There was very mild fatty infiltration in both soleus and peroneal muscles on MRI.

P2 developed the first manifestations of exercise intolerance at age 10, with frequent attacks of muscle pain and cramps after physical exercise causing nausea, vomiting, weakness, and fatigue. Symptoms gradually increased and limited her daily activities after age 35 . She could walk $5 \mathrm{~km}$ at a slow pace. Examinations at age 46 showed mild proximal upper limb weakness. CK levels varied between normal and 8,000 U/L after exercise. EMG of P2 done at the age of 51 years showed small polyphasic motor unit potentials in proximal muscles deltoideus, biceps brachii, gluteus medius, and vastus lateralis, and to a lesser extent gastrocnemius medialis, consistent with myopathic changes. Fibrillations or repetitive discharges were not detected in any of the investigated muscles. Repetitive nerve stimulation was also performed in order to exclude myasthenia gravis and showed normal results. There were no fatty degenerative changes on muscle MRI, although muscle volume was clearly reduced in all muscle groups.

Blood lactate levels did not increase during exercise tests in either sibling, and P2 developed typical symptoms of weakness, pain, and nausea after the test. Cardiac evaluation showed normal heart function in both patients.

Muscle biopsy and enzymatic studies. Mild myopathic changes were observed in both patients' samples. In P1, muscle biopsy from left tibialis anterior was consistent with increased fiber size variation, ring fibers, and slight endomysial fibrosis. Subsarcolemmal clear blebs in hematoxylin and eosin staining with enhanced periodic acid-Schiff (PAS) positivity could be observed (figure 1, A and B), but the histochemical phosphofructokinase activity was preserved (figure $1 \mathrm{C}$ ). In addition, occasional cytochrome $c$ oxidase-negative fibers occurred (figure 1D), but no additional evidence indicative of mitochondrial etiology was noted. In semithin sections, the subsarcolemmal blebs were also evident (figure 1E). On EM, a definite accumulation of nonlysosomal glycogen correlated with the light microscopic observations.

In P2's muscle biopsy, PAS-positive polyglucosan accumulates were found as well as some rimmed vacuoles. These accumulations were positive for PFKM, desmin, ubiquitin, VCP, LC3b, and p62 (figure 2) but were negative for myotilin. Accumulation of p62 and the autophagosome marker LC3b 
Figure 1 Tibialis anterior muscle biopsy of P1

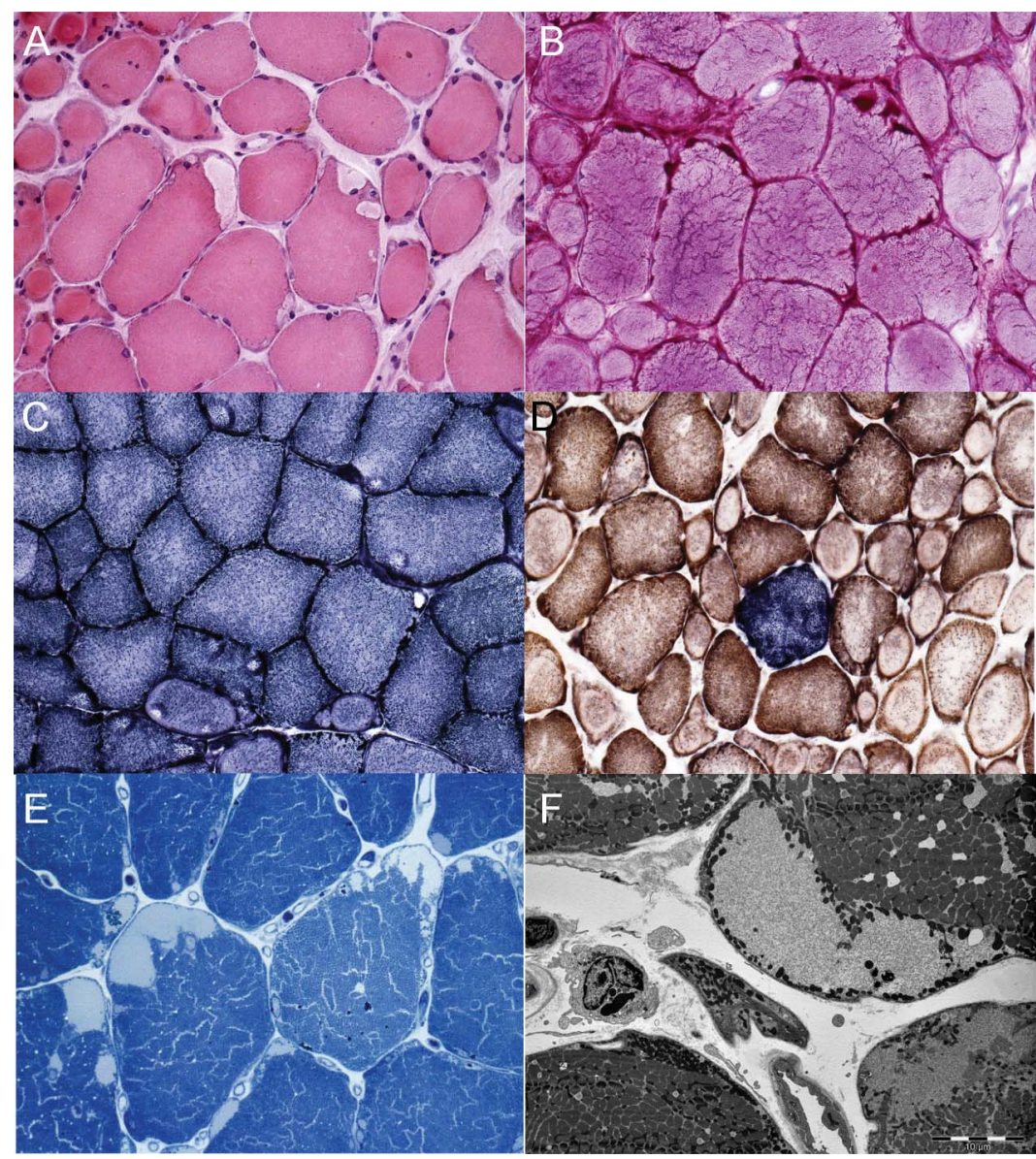

(A) Increased fiber size variation, ring fibers, slight endomysial fibrosis, and prominent clear mainly subsarcolemmal blebs. Hematoxylin and eosin staining, $\times 200$. (B) Enhancement of subsarcolemmal and partly intermyofibrillar periodic acid-Schiff (PAS) positivity. PAS staining $\times 200$. (C) Histochemical staining for phosphosphofructokinase shows preserved staining and activity $\times 200$. (D) A single cytochrome $c$ oxidase (COX)-negative fiber was observed in COX-succinate dehydrogenase (SDH) staining located at the center. COX-SDH $\times 100$. (E) Subsarcolemmal and some intermyofibrillar blebs in toluidine blue staining, plastic section $\times 400$. (F) Verified accumulation of subsarcolemmal glycogen in electron microscopy $\times 3,950$.

have been used to indicate abnormalities in the autophagic degradation pathways, and VCP is involved in proteasome-autophagy crosstalk and is a core component in endoplasmic reticulum-associated protein degradation. ${ }^{6}$ Due to sampling, the polyglucosan accumulates in the few fibers were not found in the material obtained for ultrastructural studies, as was the case in the biopsy of P1.

In contrast to muscle biopsy histochemical staining, biochemical assessment showed severely reduced enzyme activity of phosphofructokinase in muscle tissue: 71 and $82 \mathrm{nmol} / \mathrm{h} / \mathrm{mg}$ (normal range 1,844$5,328 \mathrm{nmol} / \mathrm{h} / \mathrm{mg}$ ) in the siblings, thus approximately $3 \%-4 \%$ of normal low activity.

Molecular genetic studies. Our patients' family history suggested a gene defect with recessive inheritance. Therefore, WES data were filtered for homozygous and compound heterozygous variants that were shared by the patients. The analysis revealed a homozygous c.329G $\rightarrow$ A nucleotide change in the PFKM gene (RefSeq: NM_001166686.1) in both patients (figure 3) leading to a p.R39Q change in the protein, confirmed by Sanger sequencing. No other diseasecausing variants were detected in other genes participating in glycogen metabolism. Analysis of single nucleotide polymorphisms upstream and downstream of the variant showed that the patients were homozygous for a haplotype extending at least $5.6 \mathrm{Mb}$ between the markers rs4140756 and rs10876138 on chromosome 12.

DISCUSSION In addition to clinical symptoms, the diagnosis of GSD is based on muscle pathology and exercise testing. We show here the results of 2 siblings with GSDVII and formation of polyglucosan accumulates with complex protein admixture on muscle biopsy but with normal PFK enzyme histochemistry.

The clinical manifestation in both patients was consistent with the classic form of GSDVII. ${ }^{4}$ Muscle pathology with glycogen storage, as well as exercise tests with no rise in lactate levels, were also suggestive of GSD. Molecular genetics identified a homozygous mutation, p.R39Q, in exon 4 of the PFKM gene. Previously, different mutations affecting the same position have described that result in transformation of arginine to either proline in homozygous state ${ }^{7}$ or alanine in compound heterozygous state. ${ }^{2}$ The Arg at position 39 is conserved in evolution and predicted to be part of the substrate binding site. ${ }^{8}$ In line, the p.R39Q mutation inactivates the enzyme to a $3 \%-$ $4 \%$ residual activity, thus confirming GSDVII diagnosis in our patients. Immunohistochemical studies with phosphofructokinase antibody showed normal protein expression, indicating that the missense mutation does not reduce the overall protein amount but severely reduces its enzyme activity.

Some of the GSDs, including GSDVII, are characterized by accumulation of polyglucosan bodies in addition to normal glycogen. ${ }^{9-11}$ Polyglucosan bodies are formed by the increased activation of the enzyme glycogen synthase, which is induced by the accumulation of redundant glucose-6-phosphate upstream in the glycolysis chain resulting from PFKM defect and the block in glycolysis. ${ }^{9-11}$ Immunohistochemical stainings revealed that the PAS-positive polyglucosan in P2's biopsy also labeled ubiquitin, p62, VCP, desmin, and LC3b but was negative for myotilin. The lack of myotilin in the polyglucosan suggests that the formation is a selective process in which structural sarcomeric proteins are not involved. However, ubiquitinated proteins labeled for degradation and activated autophagic response are apparently involved in this accumulation process, which has not been previously detailed in the GSDs. 
Figure $2 \quad$ Vastus lateralis biopsy of $\mathrm{P} 2$
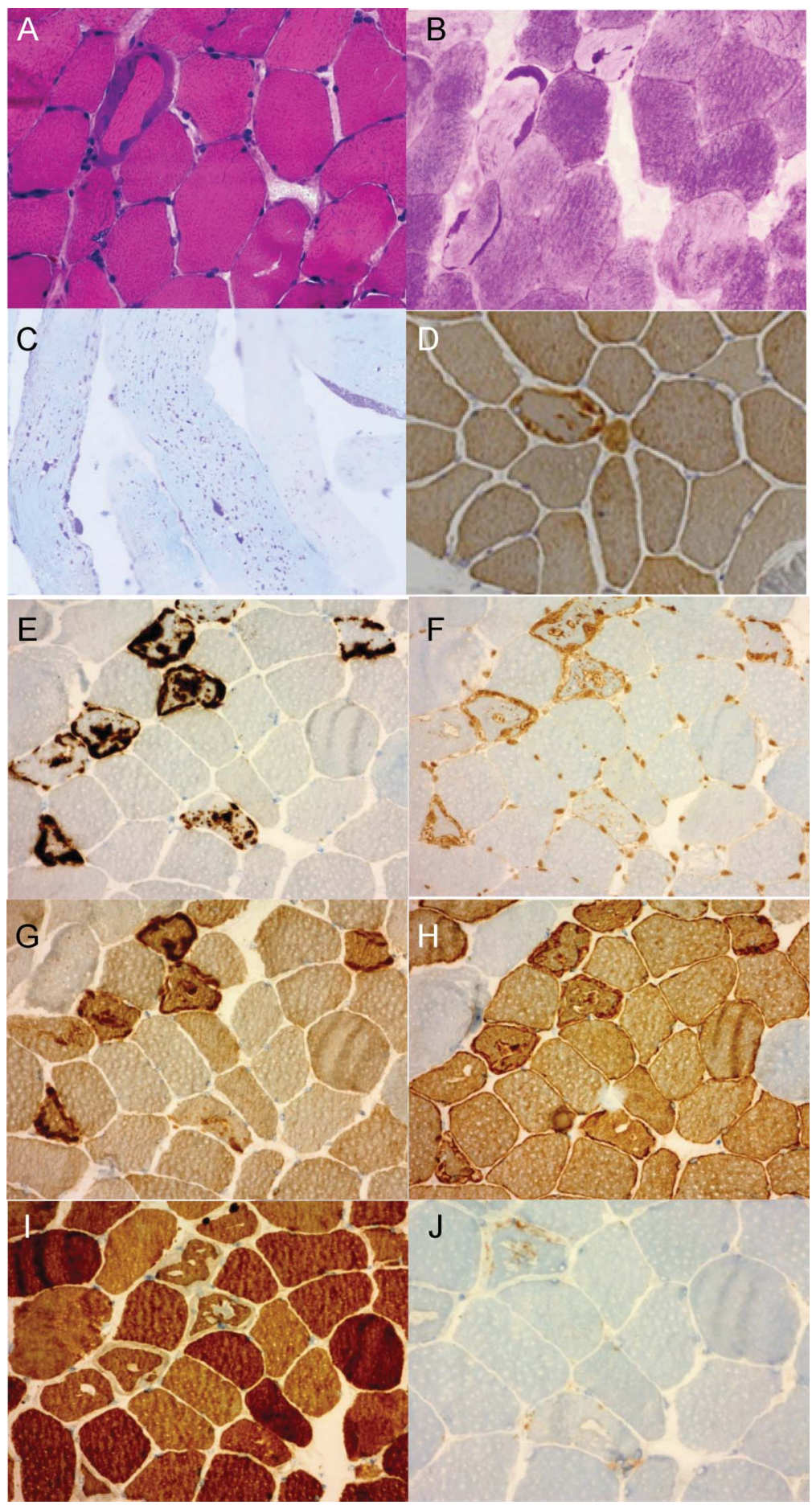

(A) Vastus lateralis muscle cryostat section hematoxylin and eosin (H\&E) staining shows basophilic subsarcolemmal aggregate in one muscle fiber and one fiber with a small rimmed vacuole. H\&E staining $\times 100$. (B) Periodic acid-Schiff (PAS) staining $\times 100$ reveals some otherwise pale fibers with prominent accumulates of PAS-positive polyglucosan material, evident also in (C) PAS semithin sections $\times 200$. (D) Immunohistochemical staining for phosphosphofructokinase shows no reduction in sarcolemmal or cytoplasmic expression. However, abnormal cytoplasmic phosphofructo-1-kinase-positive aggregates are observed in some fibers. These accumulations are unlike normal glycogen positive for (E) p62, (F) ubiquitin, $(\mathrm{G})$ valosin-containing protein, and $(\mathrm{H})$ desmin immunohistochemistry and negative for (I) myotilin, findings consistent with polyglucosan aggregates. $(\mathrm{J})$ In these fiber regions, rimmed vacuolar pathology with accumulation of light chain $3 \mathrm{~b}$-positive material is also seen (original magnification $\times 100$ in panels $E-J)$.
Figure 3 Homozygous c.329G $\rightarrow$ A nucleotide change in the PFKM gene in both patients
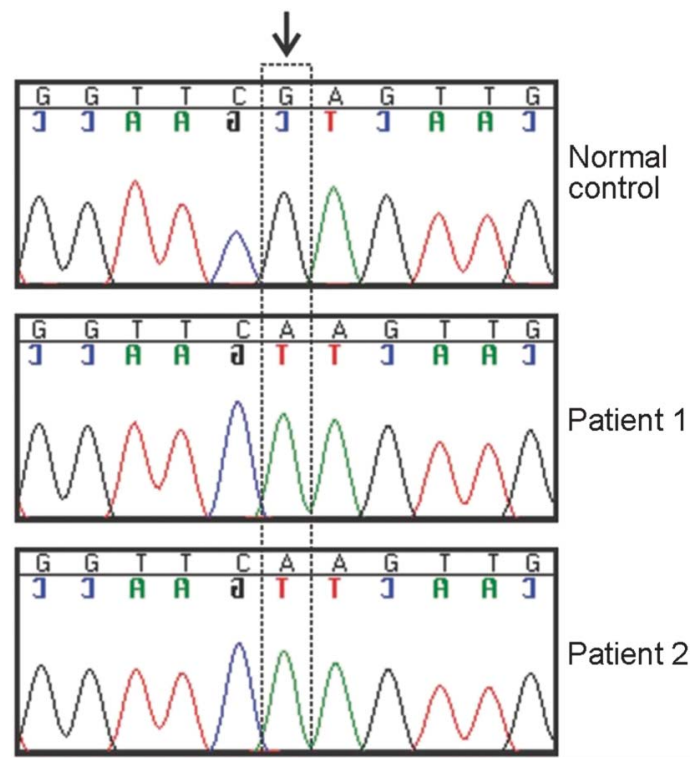

Chromatograms show the presence of the PFKM c.329G $\rightarrow$ A mutation in the patient genomic DNA but not in the normal control sample.

Our results indicate that conventional enzyme histochemistry previously used as "gold standard" for the diagnosis of GSDVII should be interpreted with caution. Instead, biochemical enzyme activity measurements and molecular genetics are recommended as the definite testing modalities for patients with clinical suspicion of this disease.

\section{AUTHOR CONTRIBUTIONS}

M.A. and J.P.: treating physicians, participated in manuscript writing. E.Y.: molecular genetic analyses, participated in manuscript writing. S.H. and A.P.: pathologic analyses, participated in manuscript writing. S.S.: treating physician, participated in manuscript writing. H.H. and K.V.: pathologic analyses, participated in manuscript writing. P.P.: physiologic analyses, participated in manuscript writing. H.T.: molecular genetic analyses, participated in manuscript writing. B.U.: treating physician, pathologic analyses, participated in manuscript writing.

\section{STUDY FUNDING}

No targeted funding reported.

\section{DISCLOSURE}

M.A. and J.P. report no disclosures. E.Y. has received research support from the Swedish Cultural Foundation in Finland. S.H., A.P., S.S., H.H., K.V., P.P., and H.T. report no disclosures. B.U. has served on editorial boards of Neuromuscular Disorders and has received research support from the Finnish Academy, the Sigrid Juselius Foundation, and the Jane and Aatos Erkko Foundation. Go to Neurology.org/ng for full disclosure forms.

Received April 23, 2015. Accepted in final form May 11, 2015.

\section{REFERENCES}

1. Tarui S, Okuno G, Ikura Y, Tanaka T, Suda M, Nishikawa M. Phosphofructokinase deficiency in skeletal 
muscle. A new type of glycogenosis. Biochem Biophys Res Commun 1965;19:517-523.

2. Sherman JB, Raben N, Nicastri C, et al. Common mutations in the phosphofructokinase-M gene in Ashkenazi Jewish patients with glycogenesis VII-and their population frequency. Am J Hum Genet 1994;55:305-313.

3. Raben N, Sherman JB. Mutations in muscle phosphofructokinase gene. Hum Mutat 1995;6:1-6.

4. Nakajima H, Raben N, Hamaguchi T, et al. Phosphofructokinase deficiency; past, present and future. Curr $\mathrm{Mol}$ Med 2002;2:197-212.

5. Sulonen AM, Ellonen P, Almusa H, et al. Comparison of solution-based exome capture methods for next generation sequencing. Genome Biol 2011;12:R94.

6. Weihl CC, Pestronk A. Sporadic inclusion body myositis: possible pathogenesis inferred from biomarkers. Curr Opin Neurol 2010;23:482-488.
7. Tsujino S, Servidei S, Tonin P, Shanske S, Azan G, DiMauro $S$. Identification of three novel mutations in non-Ashkenazi Italian patients with muscle phosphofructokinase deficiency. Am J Hum Genet 1994;54: 812-819.

8. Poorman RA, Randolph A, Kemp RG, Heinrikson RL. Evolution of phosphofructokinase: gene duplication and creation of new effector sites. Nature 1984;309:467-469.

9. Agamanolis DP, Askari AD, DiMauro S, et al. Muscle phosphofructokinase deficiency: two cases with unusual polysaccharide accumulation and immunologically active enzyme protein. Muscle Nerve 1980;3:456-467.

10. Hays AP, Hallett M, Delfs J, et al. Muscle phosphofructokinase deficiency: abnormal polysaccharide in a case of late-onset myopathy. Neurology 1981;31:1077-1086.

11. DiMauro S, Spiegel R. Progress and problems in muscle glycogenoses. Acta Myol 2011;30:96-102. 


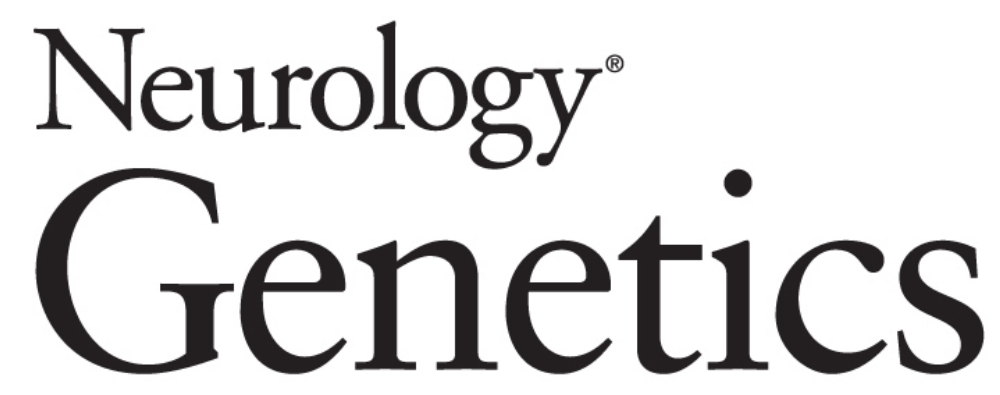

\section{PFKM gene defect and glycogen storage disease GSDVII with misleading enzyme histochemistry}

Mari Auranen, Johanna Palmio, Emil Ylikallio, et al. Neurol Genet 2015;1;

DOI 10.1212/NXG.0000000000000007

\section{This information is current as of June 4, 2015}

\section{Updated Information \&} Services

References

Citations

Permissions \& Licensing

Reprints including high resolution figures, can be found at: http://ng.neurology.org/content/1/1/e7.full.html

This article cites 11 articles, 0 of which you can access for free at: http://ng.neurology.org/content/1/1/e7.full.html\#\#ref-list-1

This article has been cited by 1 HighWire-hosted articles: http://ng.neurology.org/content/1/1/e7.full.html\#\#otherarticles

Information about reproducing this article in parts (figures,tables) or in its entirety can be found online at:

http://ng.neurology.org/misc/about.xhtml\#permissions

Information about ordering reprints can be found online: http://ng.neurology.org/misc/addir.xhtml\#reprintsus

Neurol Genet is an official journal of the American Academy of Neurology. Published since April 2015, it is an open-access, online-only, continuous publication journal. Copyright $(2015$ American Academy of Neurology. All rights reserved. Online ISSN: 2376-7839.

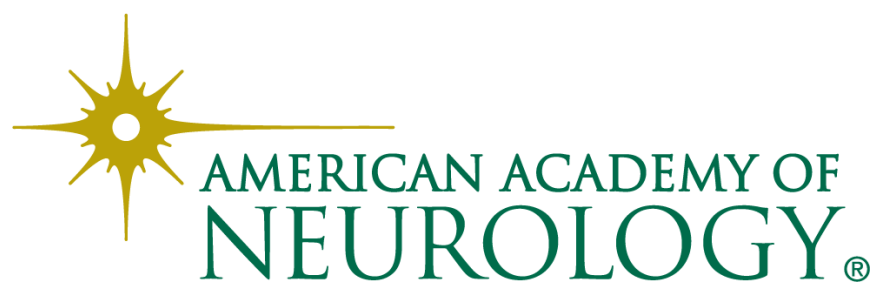

